\title{
SSinteza
}

Impact of Internet on Business Activities

\section{ELEARNING PROGRAM IN PIRAEUS BANK BELGRADE}

\author{
Bojana Vesić Antić1 ${ }^{1}$ Aleksandra Radić ${ }^{1}$, Lazar Dražeta² \\ ${ }^{1}$ Piraeus Bank Belgrade \\ ${ }^{2}$ Singidunum University, Belgrade
}

\begin{abstract}
:
In the past three years, Piraeus Bank Belgrade started using Learning Management System platform as a part of Articulate eLearning software, in order to improve training and development activities while reducing training costs. eLearning program proved reliable, user-friendly and cost-effective training and development tool as the major tangible cost appears to be license fee associated with using software. The eLearning modules were either tailored internally, by employees from all organizational units (including other country operations) or purchased externally, as a ready-to-use material from respected providers. This was enabled both by close supervision of employees who created eLearning modules, using Articulate Instructional Design instrument as well as professional assessment of externally purchased materials. Apart from tailoring practical "know-how" solutions for wide array of business topics, eLearning program proved valuable asset in personal development of employees engaged in their creation while transferring learning responsibility to first-line staff.
\end{abstract}

\author{
Key words: \\ eLearning program, \\ Articulate software, \\ training and development, \\ learning modules.
}

\section{INTRODUCTION}

Although the origin of the term eLearning is not known, it emerged with term „Online learning“", back in the 1980's. eLearning can be described as learning through usage of computer network technology, mainly via the Internet to deliver information or instructions to learners [1]. In addition, eLearning is seen as instruction itself, delivered via computer with intention to promote learning [2].

The reasonable argument would be if eLearning is somewhat different than learning in a conventional sense, like classroom and/or use of printed materials, books. This arouse a lot of controversy in the field of educational technology. It seems reasonable to claim that the general opinion is not whether one medium is better than another, because it is the instructional method that promotes learning rather than delivery device per se. Media researchers agree that eLearning offers different and likely better learning opportunities by offering different instructional methods [3]. The main question considering eLearning is not if people can learn better using computers, but which aspects of eLearning is able to help learners to acquire certain kind of knowledge [4].

Due to operational flexibility and prompt delivery, eLearning has become a popular means of learning in organ- ization or workplace settings [1]. Although there are certain gaps between corporate interests and learner needs, where number of applications did not motivate employees to learn $[5,6]$, we well present the case where changing learning strategy, coupled with full employee engagement in designing tailored eLearning modules proved effective mean in organizational learning process.

\section{WHY ELEARNING PROGRAM?}

Having recognized the need for becoming a cost-effective learning organization, training and development function of Human Resources Department in Piraeus Bank Belgrade (PBB) started the project of introducing the eLearning platform. The challenge was not just to create learning content for modules and present them to users, but rather to change the corporate culture and create atmosphere of learning organization.

Current eLearning programs often focus on technical issues of design and ignore pedagogical and organizational issues necessary to obtain effective learning process [7]. Therefore, the first objective for PBB was to design learning modules using all important principles of successful teaching and adult learning, such as: a) need to know, b) self-concept, c) prior experience, d) readiness to learn, e) learning orientation, and f) motivation to learn [8]. 
Hence, in 2012, PBB adopted the regional Learning Management System software called Articulate, eleven years after being adopted by Piraeus Bank Greece. More than 40000 organization worldwide rely on Articulate software, including 93 of the Fortune 100 companies and 19 out of 20 top-ranked universities [9]. The goal of $\mathrm{PBB}$ was clearly aligned with the following features of Articulate software: a) powerful and simple to use, b) requires well designed content needs, and c) customer-oriented to help participants learn in the most effective way.

\section{FEATURES OF ARTICULATRE SOFTWARE}

Articulate is an MS Office add-in that enables creation of eLearning modules using Power Point presentations. It supports all the features of Power Point, as well as many others specially created for making eLearning modules. Articulate software incorporates number of options that are listed below:

- Tabs allows user to explore a group of related items, walk through a list of concepts and identify members of a group or compare the differences among several objects;

- Labelled graphic identify the key elements of an image, highlight details of a photo, call out relevant parts of a graphic or explain features of a software screenshot;

- Process allows user to discover and illustrate the constituent steps, walk through a series of related items, or explain a workflow or a procedure;

- Circle diagram displays the relationship of items in a circular hierarchy, shows related items within a hierarchy, organizes concept into segments and layers or graphically depicts a philosophy or approach;

- Timeline allows user to discover the events of a time period;

- Media tour allows user to step through a series of related images;

- FAQ uncover the answers to freguently asked questions;

- Pyramid allows user to explore hierarchical relationship of related concept;

- Guided Image allows user to examine important parts of an image or diagram;

- Glossary reveals definitions of words, terms and phrases;

- Community Intereactions provide flashcards to reveal additional content associated with a term, phrase or question.

Since the platform is web-based, it allows instructor of the module to preview and tune the content before publish it through Learning Management System (LMS). Once it has been imported into the LMS platform, instructor can upload all the necessary information about the module - create special catallogue(s) where the modul is placed, insert questions and create tests and relevant exams, import any other relevant material that have to be read by participants, insert the name of an instructor and his/her contact information for any additional explanations, etc. After that, learning module is ready and users are to be enrolled.

\section{OUTCOMES OF ELEARNING PROGRAM}

Web-based learning is described as having access to learning via the use of some technology $[10,11,12]$. Due to information revolution it has become quite popular nowadays. Taking into consideration increased demands at work and time available for learning, people are keen to study from their homes by attending courses via the Internet in a relaxing atmosphere under own terms regarding. This proved particularly useful for disabled and people with special needs who were able to learn and participate in various courses without the need to leave their homes.

By the definition, eLearning allows studying at own pace. The major benefit was related to the thoroughness of the process where individual dedicated as much time to learn as needed without interruptions and imposed constrictions. The courses made using Articulate software also proved interesting, appealing and user-friendly, attracting learners' attention and keeping them focused to the topic.

The software is all-out transparent and provides various types of reports necessary to monitor the whole organizational learning process: a) list of all users of a particular module, b) list of the people who passed/failed the exam for each module, $c$ ) list of modules attended by a particular user, d) the time someone spent in learning of a particular module, etc. LMS also set learning standards for the whole organization. It requires minimum $69 \%$ achievement and maximum two exams to successfully complete any module (i.e. „Pass").

One of the key tangible benefits for organizational learning process comes from LMS cost savings. eLearning proved cost-effective solution as organization is not paying training fee and accommodation costs for external trainers. At the same time, employees remain at work during the period of learning activities that can be carried out both from the workplace and/or their home. Additional benefit comes from the fact that LMS is a regional eLearning platform with possibility to share best practice knowledge between all Piraeus Bank operations. Hence, once developed learning modules can be distributed to all the countries with no additional costs.

A possibility to regionally share best practice and knowledge on general topics is of the utmost importance. The modules are transparent, the instructors of the modules become visible to the whole Group and they are given a chance to share their experience with the others. Their know-how is now regionally available.

Furthermore, all learning modules are internally made by an expert from the organization and tailored to suit current knowledge level of module users. Table 1 shows chronology of module introduction in all four operations (countries) of Piraeus Bank who accepted eLearning program. The LMS platform in Serbia currently contains 36 modules, of which 34 are dedicated to hard skills while 2 modules aim for development of soft skills. In 2014, ad- 
ditional 20 modules are planned for launch, out of which 18 modules deal with hard skills and 2 modules with soft skills. This demonstrated versatility of eLearning program that proves capable of engaging even some traditional classroom-based modules (i.e. soft skills).

Table 1: Introduction of eLearning modules in Piraeus Bank

\begin{tabular}{|c|c|c|c|}
\hline $\begin{array}{c}\text { Operation, year } \\
\text { of LMS launch }\end{array}$ & $\begin{array}{c}\text { Externally } \\
\text { purchased } \\
\text { modules }\end{array}$ & $\begin{array}{c}\text { Internally } \\
\text { created } \\
\text { modules }\end{array}$ & $\begin{array}{c}\text { Total } \\
\text { number of } \\
\text { modules }\end{array}$ \\
\hline Greece, 2001 & 259 & 102 & 301 \\
\hline Cyprus, 2012 & 0 & 6 & 6 \\
\hline Bulgaria, 2012 & 0 & 1 & 1 \\
\hline Serbia, 2012 & 0 & 36 & 36 \\
\hline
\end{tabular}

Improvement in organizational learning process proved even more significant. Before introduction of eLearning program, there were 6.47 training hours per trained employee while two years later this reached 22.31 training hours per trained employee in PBB. Furthermore, before introduction of eLearning program a total of 370 employees get trained in any topic/module per annum while today this number increased to 500 employees.

Probably the most valuable intangible benefit of eLearning is raised awareness of PBB employees in lifelong learning pursuit of knowledge for both professional and personal reasons. The possibility to evaluate own knowledge, participate as a "knowledge worker" in development of modules and implement „know-how“ learning outcomes at the working place increased a sense of ownership over the business process.

\section{CHALLENGES OF ELEARNING PROGRAM}

Lack of interaction with other participants is probably the most obvious challenge of eLearning program. Although LMS offers possibility for a learner to see the list of participants and communicate with them via the Internet (asking questions, providing explanations), it conveys the sense of virtual reality that only simulate physical presence of people and learning process from the real world. This is particularly evident with some soft skills trainings that require live interaction within a group and personal role-modeling as a teaching tool of a trainer.

Technological limitations may impede use of Articulate software, as it requires high capacity of network and solid IT support to run the program that often contains numerous video and audio presentations. Apart from network requirements, completion rates of learning modules show that $10 \%$ employees failed to finish these web-based training courses.

Although it is not a sizeable drawback, it is worth of organizational attention as it refers only to employees who attended certain learning modules with intention to complete them and not to those who consciously avoid their attendance.
In spite of the fact that learning module is often submitted to the platform by a single expert it is laborious effort that requires collaboration with number of employees from various business units. Hence, cross-functional alignment proved difficult as it requires a great deal of tact and diplomacy to work with coauthors and get compliance from key stakeholders, i.e. different functions throughout the organization, before reaching the final approval to upload learning module on the platform.

However, probably the biggest challenge lies in the quality assurance of posted modules (,garbage in - garbage out"). Process of creating learning modules is not standardized, thus authors approach the problem from a different perspective. Although some authors are technically well educated with substantial expertise in certain topic(s), they lack capability to express themselves to a larger audience that may render useless posted materials. This is also a real threat to the effectiveness of eLearning program as it can discourage learners to attain „unproven" or "unfit" modules and thus undermine the overall learning process in an organization.

\section{CONCLUSION}

Introduction of eLearning program in $\mathrm{PBB}$ brought positive change in training and development activities while increased employees' awareness of the need for personal educational update in different business areas. Consequently, eLearning modules resulted in satisfactory learning outcome, particularly with hard skills courses. The adversary effect of web-simulated environment is obvious only to some soft skills courses that heavily rely on personal interaction within a training group. On the other side, major challenge for the effective utilization of electronic courses in the future is to align the quality of learning modules, both through standardized operating procedure(s) and personal development of instructors.

Articulate software proved to be user-friendly and cost-effective solution that supports the overall organizational learning process. Its features significantly help initiating the concept of learning organization while increasing training hours of employees more than 3 -fold in two years. Together with current changes in business process, eLearning program proved one of the key strategies to help influence development of individual and team capabilities while reducing silo mentality and thus improving organizational culture in PBB.

\section{REFERENCES}

[1] Wang, M., Ran, W., Liao, J., \& Yang, S. J. H., A Performance-Oriented Approach to E-Learning in the Workplace. Educational Technology \& Society, 13 (4), 167-179, 2010.

[2] Clark, T. \& R.E. Mayer, ,eLearning and the Science of Instruction“. San Francisco: Jossey-Bass, 2003.

[3] Clark, T., Virtual schools: Trends and issues - A study of virtual schools in the United States. San Francisco, CA: Western Regional Educational Laboratories, 2001. 
[4] Mayer R.E., „The Psychology of Learning and Motivation“, San Diego: Academic Press, 41, pp. 85-139, 2002.

[5] Brink B., Munro, J. \& M. Osborne, Online learning technology in an SME work-based setting. Educational Technology \& Society, 5 (2), 81-86, 2002.

[6] Servage, L., Strategizing for workplace e-learning: some critical considerations. The Journal of Workplace Learning, 17 (5/6), 304-317, 2005.

[7] Tynjälä, P. \& Häkkinen, P., E-learning at work: theoretical underpinnings and pedagogical challenges. The Journal of Workplace Learning, 17(5/6), 318-336, 2005.

[8] Knowles, M. S., Swanson, R. A., \& E. F.Holton, „The adult learner: The definitive classic in adult education and human resource development" (6th ed.), California: Elsevier Science and Technology Books, 2005
[9] https://www.articulate.com/

[10] Benson, A., Using online learning to meet workforce demand: A case study of stakeholder influence. Quarterly Review of Distance Education, 3(4), 443-452, 2002.

[11] Conrad D., Deep in the hearts of learners: Insights into the nature of online community. Journal of Distance Education, 17(1), 1-19, 2002.

[12] Carliner, S. „An overview of online learning“ (2nd ed.). Armherst, MA:Human Resource Development Press, 004. 